\title{
Nanosized Iron Oxide Uniformly Distributed on 3D Carbon Nanosheets: Efficient Adsorbent for Methylene Blue
}

\author{
Jiaqin Chen, Mei Ming, Caili Xu, Jie Wu *, Yi Wang, Ting Sun, Yun Zhang and Guangyin Fan \\ College of Chemistry and Materials Science, Sichuan Normal University, Chengdu 610068, China \\ * Correspondence: wujie@sicnu.edu.cn; Tel.: +86-28-8476-0802
}

Received: 21 May 2019; Accepted: 11 July 2019; Published: 19 July 2019

\begin{abstract}
Magnetic carbon materials as adsorbents for dye removing have attracted increasing attention because of their magnetic separation feature. However, the immobilization of large magnetic particles on a carbon matrix greatly decreases the available sites for adsorption, resulting in a low adsorption capacity. The synthesis of magnetic carbon materials as adsorbents for dye adsorption with high adsorption capacity remains challenging. Herein, porous carbon (PC) was firstly synthesized through the calcination of macroporous acrylic type cation exchange resin. The as-prepared PC was applied as a matrix to deposit nano-sized $\mathrm{Fe}_{3} \mathrm{O}_{4}$ nanoparticles (MPC) via a facile one-pot solvothermal strategy. The nano-sized $\mathrm{Fe}_{3} \mathrm{O}_{4}$ nanoparticles (5.19 $\mathrm{nm}$ in diameter) are uniformly distributed on the PC surface. The MPC possesses an exceptional performance for methylene blue removal $\left(q_{e}=\right.$ $214.4 \mathrm{mg} \mathrm{g}^{-1}$ ) at room temperature, outperforming most previous magnetic carbon adsorbents. The large surface area of the MPC originated from the combined advantages of PC and nano-sized $\mathrm{Fe}_{3} \mathrm{O}_{4}$ must be ascribed to the high performance of MPC composite toward methylene blue adsorption.
\end{abstract}

Keywords: methylene blue; adsorbent; magnetic composite; porous carbon

\section{Introduction}

Organic dyes are useful chemicals, which are widely applied in industry including textiles, paper, plastics, tannery, and paints, etc. [1]. The industrial effluents containing organic dyes cause environmental crises because of their high biotoxicity and potentially mutagenic and carcinogenic effects [2,3]. Considerable efforts have been exerted to remove dye contaminants by using methods such as adsorption [4], photocatalytic degradation [5], precipitation and microbiological coagulation [6], and biosorption [7]. Adsorption is considered as one of the most promising avenues for treating dye pollutants [1]. Various materials have been investigated as adsorbents for treating dye pollutants, among which carbon materials have shown good adsorption performance because of their superior characteristics of large surface areas and structure properties. However, complicated and time-consuming procedures are required to recover these adsorbents from wastewater, thereby prohibiting their recyclability and enhancing the cost of adsorbent regeneration [8]. Hence, developing new types of adsorbents with high adsorption capacity and removal efficiency remains challenging.

Magnetic materials have shown promise as adsorbents for remedying environmental pollutions from organic dyes because of the remarkable feature of magnetic separation compared with the abovementioned methods [9-11]. Until now, $\mathrm{Fe}_{3} \mathrm{O}_{4}$ based magnetic carbon materials have attracted considerable research interest for treating cationic dyes. For instance, $\mathrm{Ai}$ and co-workers developed a solvothermal method for the synthesis of $\mathrm{RGO} / \mathrm{Fe}_{3} \mathrm{O}_{4}$ composite as an adsorbent for methylene blue (MB) adsorption. Although the separation problem was effectively overcome, the removal efficiency was not satisfied enough because of the low surface area of reduced graphene oxide(RGO) produced 
by a chemical oxidation-exfoliation-reduction process and the relatively large particle size of $\mathrm{Fe}_{3} \mathrm{O}_{4}$ $(200 \mathrm{~nm})$ [11]. They further discovered that the maximum adsorption capacity toward MB removal could be improved to $48.06 \mathrm{mg} \mathrm{g}^{-1}$ when the matrix RGO was replaced by multi-walled carbon nanotubes (MWCNTs) $\left(\mathrm{Fe}_{3} \mathrm{O}_{4} / \mathrm{MWCNTs}\right)$ [8]. Despite these advances, the location of micro-sized $\mathrm{Fe}_{3} \mathrm{O}_{4}$ particles on these carbon materials significantly reduces the specific surface area, thereby reducing the original adsorption capacities and removal efficiencies. To solve the abovementioned problems, exploring carbon materials with large surface areas and deposition of nano-sized $\mathrm{Fe}_{3} \mathrm{O}_{4}$ are expected to be a promising pathway to enhance adsorption performance toward $\mathrm{MB}$ removal.

Herein, porous carbon (PC) with large surface area was synthesized and explored as a matrix for depositing nano-sized $\mathrm{Fe}_{3} \mathrm{O}_{4}$ through a solvothermal reaction. The achieved magnetic porous carbon (MPC) was employed for MB adsorption in aqueous solution. Effects of contact time, solution $\mathrm{pH}$, and initial dye concentration on the adsorption property of MPC for MB removing were investigated. The kinetics and thermodynamics of MB adsorption on MPC were further studied in detail. The highest adsorption capacity of $214.4 \mathrm{mg} \mathrm{g}^{-1}$ with the solution $\mathrm{pH}$ of 11 was obtained at $25^{\circ} \mathrm{C}$, outperforming most of the reported magnetic adsorbent for MB adsorption. The strong magnetic sensitivity of MPC favors the recovery of the adsorbent from the aqueous solution and used for the next adsorption experiment.

\section{Materials and Methods}

The used materials and characterization are illustrated in the Supporting Information.

\subsection{Synthesis of $M P C$}

MPC was simply prepared by a one-step solvothermal process by using PC as a matrix (Scheme 1). Specifically, the desirable amount of $\mathrm{PC}(0.1 \mathrm{~g}), \mathrm{FeCl}_{3} \cdot 6 \mathrm{H}_{2} \mathrm{O}(0.54 \mathrm{~g})$, sodium acetate $(1.5 \mathrm{~g})$, and sodium acrylate anhydrous $(1.5 \mathrm{~g})$ were added into $20 \mathrm{~mL}$ of ethylene glycol and diethylene glycol with a volume ratio of 1:19. After being treated by ultrasonication, the uniform suspension was introduced to an autoclave and sealed before heating at $220^{\circ} \mathrm{C}$ for $10 \mathrm{~h}$. The resulting suspension was isolated with the aid of a magnet and treated by washing cycles with ethanol for three times.

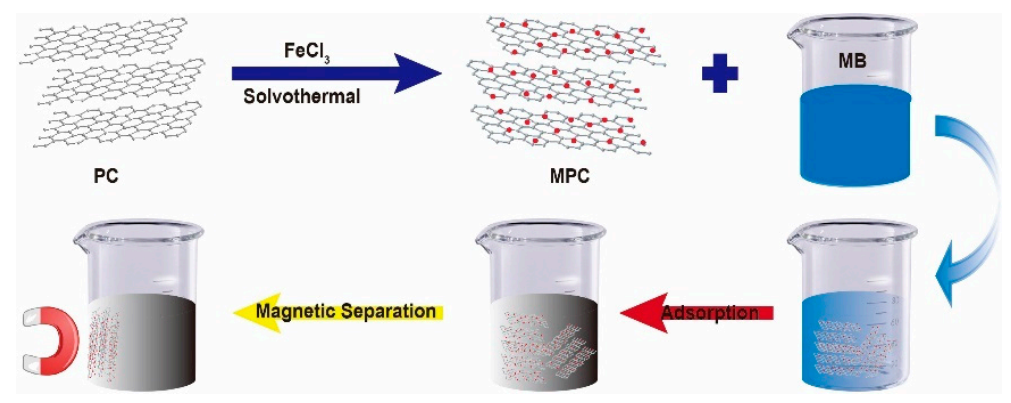

Scheme 1. Schematic illustration of the synthesis and application of the matrix porous carbon (MPC) for MB adsorption.

\section{2. $M B$ Adsorption}

MB adsorption tests were performed in a thermo-stated shaker by using Erlenmeyer flasks (100 mL). Typically, $10 \mathrm{mg}$ MPC and $50 \mathrm{~mL} \mathrm{MB}$ solution with different initial concentrations $\left(45-55 \mathrm{mg} \mathrm{L}^{-1}\right)$ at natural $\mathrm{pH}$ were transferred into the Erlenmeyer flask, followed by shaking with a speed of $200 \mathrm{rpm}$ at $25^{\circ} \mathrm{C}$. To calculate the adsorption capacity, the sample was withdrawn from the Erlenmeyer flask at predetermined time interval. Then, the sample was analyzed with a Unico UV-4802S spectrophotometer to determine the retained $\mathrm{MB}$ concentration. The adsorption capacity was evaluated according to the reported method [11].

The adsorption tests were performed at different $\mathrm{pH}$ ranging from 3 to 11 to study the corresponding changes in adsorption capacity of MB on MPC. The initial $\mathrm{pH}$ of the MB solution was adapted with the 
use of $\mathrm{HCl}$ or $\mathrm{NaOH}$ aqueous solution. Additionally, the adsorption of MB with MPC was conducted at different temperatures of 25,35 , and $45^{\circ} \mathrm{C}$ to determine the adsorption isotherms.

To study the regeneration and reusability of MPC for MB adsorption, the MPC was isolated from the solution with the help of magnet after the first adsorption test was finished (Scheme 1). The recovered MPC was rinsed by ethanol several times and then dried under vacuum at $80{ }^{\circ} \mathrm{C}$ overnight. After fresh MB solution with a concentration of $55 \mathrm{mg} \mathrm{L}^{-1}(\mathrm{pH}=11)$ was introduced, the next reusability test of MPC was started.

\section{Results and Discussion}

\subsection{Sample Characterizations}

Figure 1a displays the SEM image of PC, in which typical 3D carbon nanosheets are observed. The microstructural morphology of the MPC was determined by TEM. It is observed that the MPC surface is covered with large quantities of well-dispersed spherical particles (5.2 nm in diameter) through the solvothermal process (Figure $1 \mathrm{~b}-\mathrm{c}$ ). The HRTEM image in Figure $1 \mathrm{~d}$ further confirms the synthesis of MPC via observing the typical (400) facet of $\mathrm{Fe}_{3} \mathrm{O}_{4}$ with a d-spacing of $0.21 \mathrm{~nm}$. The corresponding elemental mapping analysis clearly shows that the $\mathrm{O}, \mathrm{Fe}$ and $\mathrm{C}$ elements are homogeneously distributed on the surface of the PC (Figure 1e-h). TEM results have demonstrated that the nano-sized $\mathrm{Fe}_{3} \mathrm{O}_{4}$ has been successfully synthesized and anchored on the PC matrix.

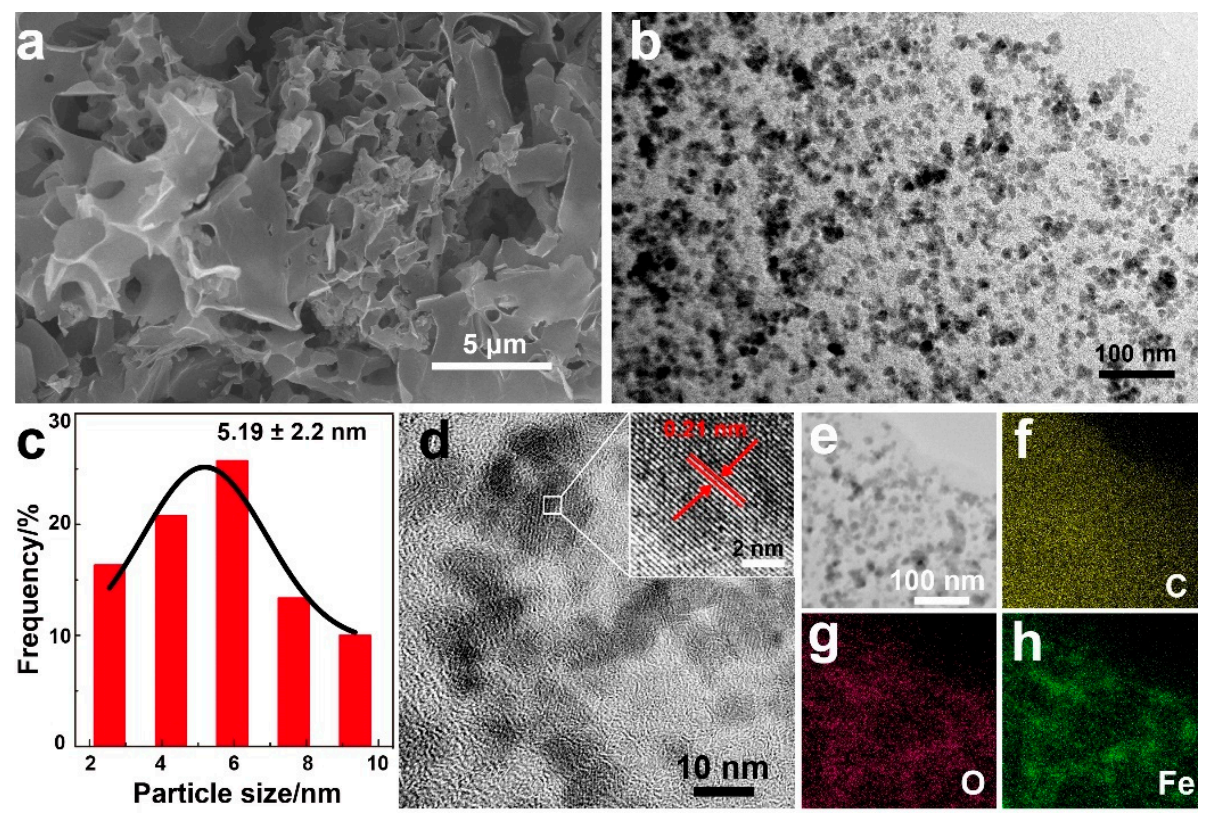

Figure 1. (a) SEM image of PC; (b) TEM image of MPC; (c) Particle size distribution of MPC; (d) HRTEM images of the MPC and (e-h) STEM-EDS mapping images of MPC.

XRD characterization was employed to determine the chemical structure of PC and MPC. As shown in Figure 2a, two diffraction peaks situated at $2 \theta=26.2^{\circ}$ and $44.4^{\circ}$ are detected in XRD pattern of PC, corresponding the (002) and (101) facets of the graphitic carbon [12]. In addition, seven new peaks at $30.1^{\circ}, 35.5^{\circ}, 43.1^{\circ}, 53.5^{\circ}, 57.0^{\circ}, 62.6^{\circ}$, and $65.8^{\circ}$ are obtained in the XRD pattern of MPC, which are assigned to the (220), (311), (400), (422), (511), (440), and (531) reflections of $\mathrm{Fe}_{3} \mathrm{O}_{4}$ (JCPDS No. 65-3107). XRD results have shown that the MPC is successfully prepared by the one-pot solvothermal process, consistent with the TEM results. Figure $2 b$ illustrates the magnetic hysteresis loops of MPC composite. The material exhibits a saturation magnetization of $20.73 \mathrm{emu} \mathrm{g}^{-1}$, benefiting for its separation and recycling. 

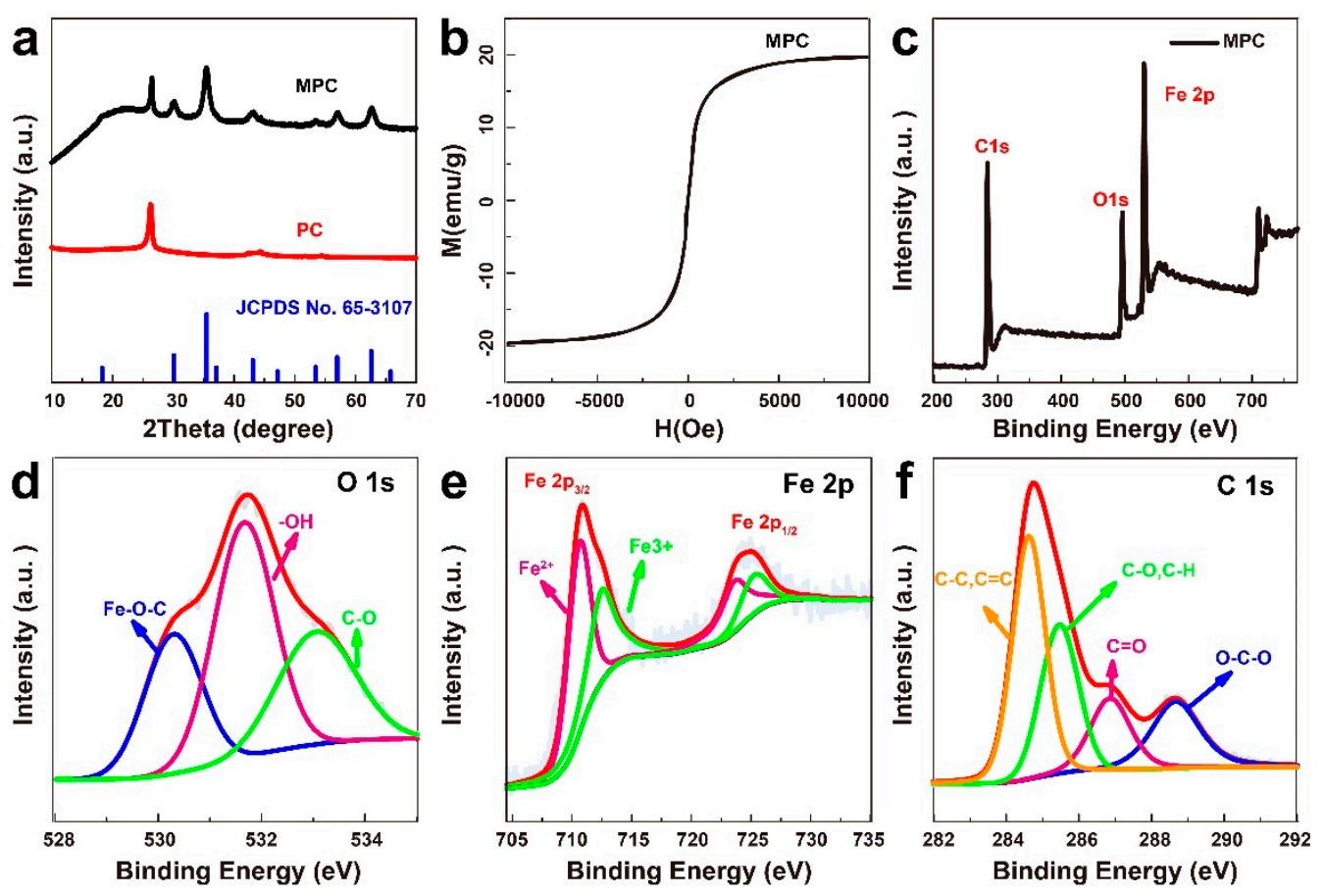

Figure 2. (a) XRD patterns of porous carbon (PC) and MPC; (b) Vibrating sample magnetometer (VSM) curve and (c) XPS fully spectrum of MPC; high-resolution spectra of (d) O1s, (e) Fe2p, and (f) C1s.

An XPS survey scan was conducted to analyze the surface compositions of MPC. The XPS signals corresponding to $\mathrm{C}, \mathrm{O}$, and Fe elements were distinctively observed in the sample (Figure 2c), consistent with the EDS mapping results. High-resolution spectra of each element were recorded to identify their chemical states. Figure $2 \mathrm{~d}$ shows the high-resolution O1s spectrum of MPC, in which the typical peaks indexed to Fe-O-C [13], -OH [14], and C-O [15] bonds are detected, respectively. These results verify the strong chemical interaction between the $\mathrm{Fe}_{3} \mathrm{O}_{4}$ and $\mathrm{PC}$ matrix, which allows the tight attachment of $\mathrm{Fe}_{3} \mathrm{O}_{4}$ nanoparticles, and thereby greatly improves the stability and recyclability of the MPC adsorbent. The Fe 2p spectrum in Figure 2e can be deconvoluted into two predominant peaks at 710.60 [16] and $712.49 \mathrm{eV}$ [17] corresponding to the $\mathrm{Fe}^{2+}$ and $\mathrm{Fe}^{3+}$ species, suggesting the formation of $\mathrm{Fe}_{3} \mathrm{O}_{4}$ phase in the composite [1]. Regarding the $\mathrm{C} 1 \mathrm{~s}$ spectrum (Figure 2f), the fitted peaks corresponding to $\mathrm{C}-\mathrm{C}$, $\mathrm{C}-\mathrm{OH}, \mathrm{C}$ (epoxy and alkoxy), and $\mathrm{HO}-\mathrm{C}=\mathrm{O}$ bonds are observed, respectively [1,18-21]. Moreover, the presence of oxygen-containing groups on MPC can enhance the hydrophilicity of MPC, benefitting its dispersion in aqueous solution.

Figure $3 \mathrm{a}, \mathrm{b}$ shows the $\mathrm{N}_{2}$ sorption isotherms of PC and MPC, in which the typical type IV isotherms are observed [22]. According to the calculation results, it is discovered that the attachment of $\mathrm{Fe}_{3} \mathrm{O}_{4} \mathrm{NPs}$ on the PC surface leads to a decrease of BET specific surface area from 1174.1 to $622.2 \mathrm{~m}^{2} \mathrm{~g}^{-1}$, accompanying by the decline of pore volume from 0.75 to $0.54 \mathrm{~cm}^{3} \mathrm{~g}^{-1}$. This could be ascribed to the deposition of the relatively small $\mathrm{Fe}_{3} \mathrm{O}_{4} \mathrm{NPs}$ and the overlap of the PC surface by $\mathrm{Fe}_{3} \mathrm{O}_{4}$ NPs [10,23-25]. However, it is conceivable that the as-synthesized MPC composite will exhibit excellent adsorption performance toward dyes removal due to its retained high surface area as well as pore volume.

\subsection{Effect of Contact Time}

Adsorption capacity and removal efficiency are critical factors to evaluate the performance of the adsorbents for treating dye pollutions in aqueous solution. Thus, a series of experiments for MB adsorption on MPC were firstly performed at different initial concentrations. The adsorption capacity for MB with MPC drastically enhances at the initial adsorption stage with all initial concentrations (Figure 3c). Then, the variation tendency becomes slow with the extension of time. The observation of the flat part of the curve in the graph means that the weight of adsorbed MB molecules remains 
constant, suggesting the achievement of equilibrium adsorption. This phenomenon can be explained by the following reasons. Initially, MPC adsorbent provides adequate vacant surface sites for MB, whereas the number of such sites decreases with increasing time due to the occupation of the absorbed MB molecules. Owing to the repulsive forces between the solute molecules on the solid and bulk phases, the residual MB molecules in aqueous solution are difficult to adsorb, which thereby leads to the slow increase of adsorption compacity [8]. On the contrary, removal efficiency for MB onto MPC reduces by increasing the initial MB concentration (Figure 3d). It could be interpreted by the following reasons. Generally, the vacant adsorption sites keep constant when the dose of adsorbent is fixed. Thus, low initial concentration of adsorbent leads to a higher removal efficiency, whereas a higher initial concentration results in the reduction of removal efficiency [8].
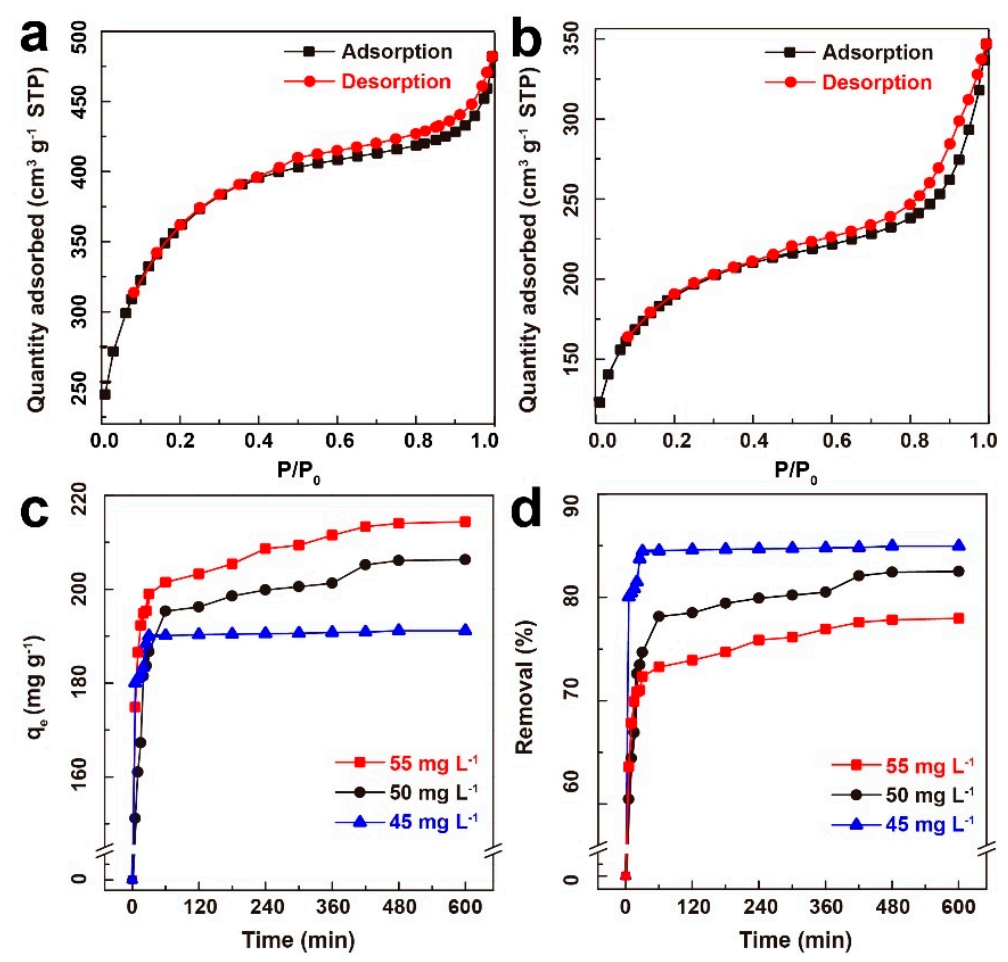

Figure 3. $\mathrm{N}_{2}$ adsorption-desorption isotherms of (a) PC and (b) MPC; (c,d) Plots of $\mathrm{q}_{\mathrm{e}} \mathrm{vs.}$ contact time toward $\mathrm{MB}$ adsorption on MPC at different $\mathrm{MB}$ concentrations $\left(\mathrm{C}_{0}: 45,50\right.$, and $55 \mathrm{mg} \mathrm{L}^{-1}, 298 \mathrm{~K}$, $\mathrm{pH}=11$ ) and the corresponding removal efficiency.

\subsection{Effect of $p H$}

Figure 4a shows the adsorption performance of MPC toward MB removing at various $\mathrm{pH}$ values from 3 to 11. Note that the amount of absorbed MB by MPC adsorbent gradually increases with the elevation of solution $\mathrm{pH}$. The results indicate the significant role of solution $\mathrm{pH}$ on the performance of MPC adsorbent. It was reported that surface property of adsorbent and structure of dye molecules played important roles in determining the relationship between the adsorption capacity and $\mathrm{pH}$ values [1]. Previous results have indicated that the adsorbent with the presence of oxygen-containing groups is negatively charged in basic solution [26]. Figure 4a shows the Zeta potentials of MPC in different solution $\mathrm{pH}$. A decreased Zeta potential is observed with the investigated $\mathrm{pH}$ range and the negatively charged surface of the MPC was observed in the $\mathrm{pH}$ range from 4-10. Note that the number of negatively charged surface sites on MPC increases with the elevation of the solution $\mathrm{pH}$ from 4 to 10 [1]. Therefore, the positive effect of solution $\mathrm{pH}$ on the adsorption capacity of the MPC must be ascribed to the increase of electrostatic attraction between the cationic MB molecule and the negatively charged surface of MPC. The optimal performance of MPC for MB adsorption was achieved at $\mathrm{pH}=$ 11 with the highest adsorption capacity of $214.4 \mathrm{mg} \mathrm{g}^{-1}$. Of special note, the MPC presents the best 
adsorption capacity of MB compared to the reported adsorbents, such as $\mathrm{Fe}_{3} \mathrm{O}_{4} / \mathrm{CNPs}$ [27], MCS [28], magnetic graphene-carbon [26], MPCMs-0.25 [29], $\gamma$ - $\mathrm{Fe}_{2} \mathrm{O}_{3} / \mathrm{C} \mathrm{NP}$ [30], $\mathrm{Fe}_{3} \mathrm{O}_{4} @ \mathrm{ZIF}-8$ core-shell [31], hydrotalcite-dodecylsulfate/Fe oxide [32], magnetic cellulose/GO [33], magnetic $\mathrm{ZnO} / \mathrm{ZnFe}_{2} \mathrm{O}_{4}$ [34], and $\mathrm{RGO} / \mathrm{Fe}_{3} \mathrm{O}_{4}[35]$ (Figure $4 \mathrm{~b}$ and Table S1).
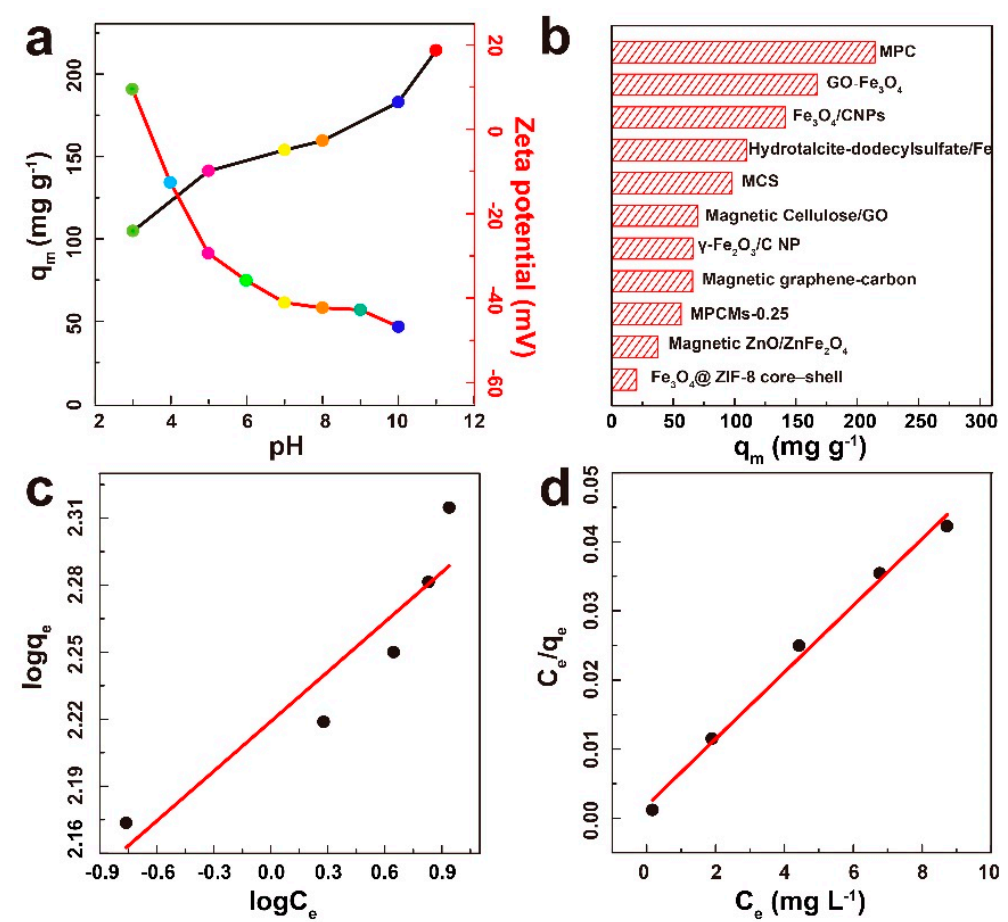

Figure 4. (a) Adsorption compacity vs. initial solution $\mathrm{pH}$ for $\mathrm{MB}$ removal on $\mathrm{MPC}$ and the corresponding Zeta potential; (b) Comparison of the adsorption capacities of MB on various adsorbents; (c) Freundlich and (d) Langmuir adsorption isotherms of MB with MPC.

\subsection{Adsorption Isotherms}

To get specific information on isotherm parameters associated with $\mathrm{MB}$, the collected adsorption data were analyzed using Langmuir and Freundlich isotherm models [36,37]. Langmuir and Freundlich isotherm models are presented by Equations (1) and (2), where $k_{L}$ represents Langmuir constant $\left(\mathrm{L} \mathrm{mg}^{-1}\right), q_{e}$ denotes the equilibrium adsorption compacity $\left(\mathrm{mg} \mathrm{g}^{-1}\right), q_{\max }$ is the Langmuir monolayer adsorption capacity $\left(\mathrm{mg} \mathrm{g}^{-1}\right), K_{f}$ is Freundlich constant $\left(\mathrm{L} \mathrm{mg}^{-1}\right), 1 / \mathrm{n}$ is the empirical parameter in terms of adsorption capacity and intensity. Figure $4 c$,d illustrates the equilibrium isotherms for $\mathrm{MB}$ adsorption by using MPC as an adsorbent. The data of the equilibrium adsorption calculated from Langmuir and Freundlich isotherm models are shown in Table 1. As can be seen from Figure 4c,d and Table 1, the experimental data is not well correlated with the Freundlich model, whereas the data matches well with Langmuir model. This finding suggests that MB adsorption on the adsorbent surface is homogeneous. Moreover, the equilibrium parameter $R_{\mathrm{L}}$, which can be estimated by Equation (3), is a useful parameter to determine the feasibility of adsorption [38]. The $R_{\mathrm{L}}$ values were calculated to be 0.00674-0.00822 for MB adsorption on MPC, suggesting that the adsorption of MB over MPC was a favorable process [39].

$$
\begin{gathered}
\frac{C_{e}}{q_{e}}=\frac{C_{e}}{q_{\max }}+\frac{1}{q_{\max } k_{L}} \\
\log q_{e}=\log K_{f}+\frac{1}{n} \log C_{e} \\
R_{L}=\frac{1}{1+k_{L} C_{0}}
\end{gathered}
$$


Table 1. Isotherm parameters for adsorption of MB onto MPC.

\begin{tabular}{ccccccc}
\hline \multirow{2}{*}{ Temperature (K) } & \multicolumn{3}{c}{ Langmuir } & \multicolumn{3}{c}{ Freundlich } \\
\cline { 2 - 7 } & $\boldsymbol{q}_{\max }\left(\mathbf{m g ~ g}^{-\mathbf{1}}\right)$ & $\left.k_{L} \mathbf{~ L ~ m g ~}^{-\mathbf{1}}\right)$ & $\mathbf{R}^{\mathbf{2}}$ & $\mathbf{1 / n}$ & $\boldsymbol{K}_{f}\left(\mathbf{L ~ m g}^{-\mathbf{1}}\right)$ & $\mathbf{R}^{\mathbf{2}}$ \\
\hline 293 & 207.04 & 2.68 & 0.9895 & 0.0741 & 165.6 & 0.8308 \\
\hline
\end{tabular}

\subsection{Adsorption Kinetic Studies}

The pseudo-first-order and pseudo-second-order kinetic models can be expressed as Equations (4) and (5), respectively. Table 2 lists the kinetic constants calculated from the linear regression of the pseudo-first-order and pseudo-second-order models as shown in Figure $5 a, b$. The $R^{2}$ values determined according to the pseudo-first-order model are relatively low. Furthermore, the corresponding $q_{e, \text { cal }}$ values are not consistent with the $q_{e, \exp }$ values obtained from the experimental data. However, the $\mathrm{R}^{2}$ values estimated via the pseudo-second-order model are higher than 0.99 and the calculated $q_{e, \mathrm{cal}}$ values fitted well with the experimental data. This finding indicates that the kinetic for MB adsorption on MPC can be explained by the pseudo-second-order kinetic model.

$$
\begin{gathered}
\log \left(q_{e}-q_{t}\right)=\log q_{e}-\frac{k_{1} t}{2.303} \\
\frac{t}{q_{t}}=\frac{1}{k_{2} q_{e}^{2}}+\frac{t}{q_{e}}
\end{gathered}
$$
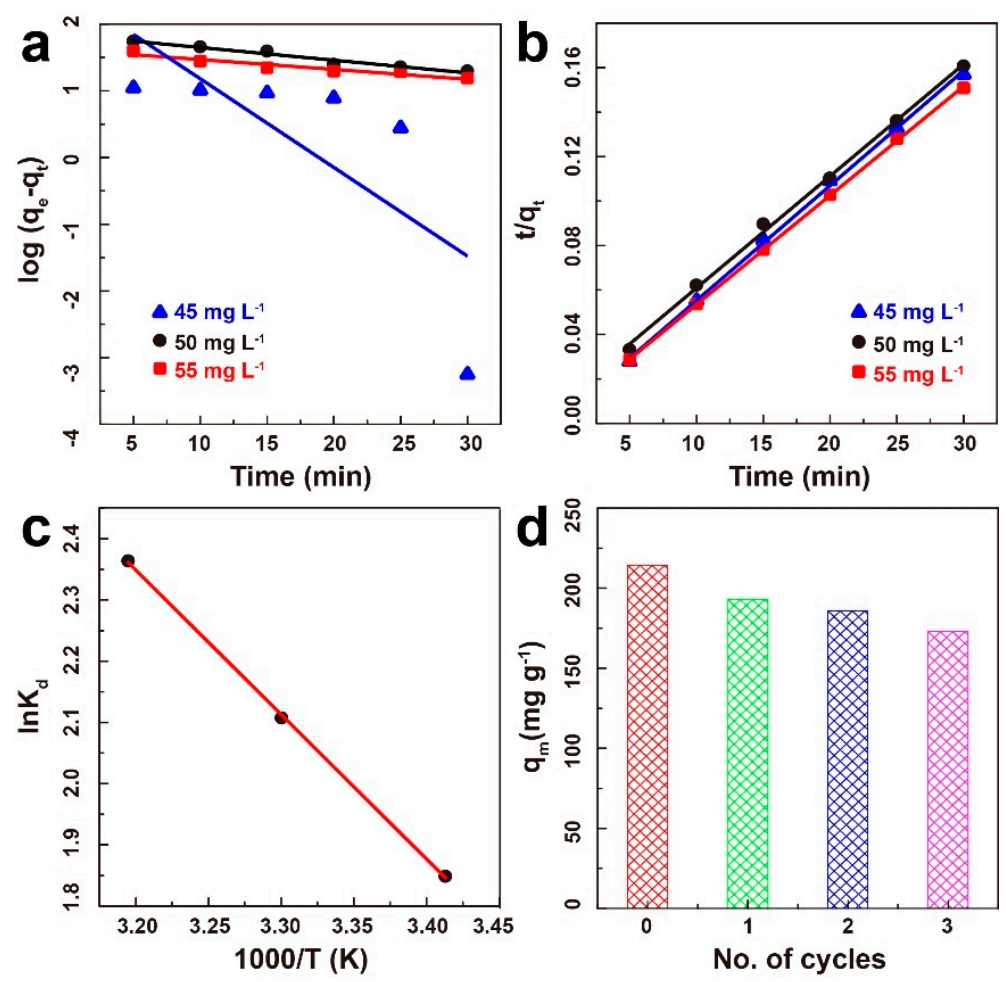

Figure 5. (a) Pseudo-first-order and (b) pseudo-second-order kinetics for MB adsorption on MPC; (c) Van't Hoff plot; (d) Adsorption capacity of MB on MPC in three successive cycles. 
Table 2. Kinetic parameters for adsorption of MB onto MPC.

\begin{tabular}{|c|c|c|c|c|c|c|c|}
\hline \multirow[b]{2}{*}{$C_{0}(\mathrm{mg} / \mathrm{L})$} & \multicolumn{3}{|c|}{ Pseudo-First-Order Kinetics } & \multirow[b]{2}{*}{$\begin{array}{c}k_{1} \\
\left(\min ^{-1}\right)\end{array}$} & \multicolumn{3}{|c|}{ Pseudo-Second-Order Kinetics } \\
\hline & $\begin{array}{c}q_{e, \mathrm{cal}} \\
\left(\mathrm{mg} \mathrm{g}^{-1}\right)\end{array}$ & $\begin{array}{c}q_{e, \exp } \\
\left(\mathrm{mg} \mathrm{g}^{-1}\right)\end{array}$ & $\mathbf{R}^{2}$ & & $\begin{array}{c}k_{2} \\
\left(\mathrm{~g} \mathrm{mg}^{-1} \min ^{-1}\right)\end{array}$ & $\begin{array}{c}q_{e, \mathrm{cal}} \\
\left(\mathrm{mg} \mathrm{g}^{-1}\right)\end{array}$ & $\mathbf{R}^{2}$ \\
\hline 45 & 323.05 & 191.15 & 0.3061 & 0.0561 & 0.00753 & 193.42 & 0.9987 \\
\hline 50 & 69.21 & 206.39 & 0.0439 & 0.0576 & 0.00239 & 198.81 & 0.9974 \\
\hline 55 & 46.25 & 214.40 & 0.0341 & 0.0567 & 0.00549 & 203.67 & 0.9998 \\
\hline
\end{tabular}

\subsection{Thermodynamic Study}

The thermodynamic parameters can be calculated according to Equations (6) and (7). The $\Delta \mathrm{G}^{0}$ values were calculated to be negative at the investigated temperatures (Table 3), suggesting the spontaneous nature of MB adsorption on MPC. As shown in Figure $5 c$, the values of $\Delta \mathrm{H}^{0}$ and $\Delta \mathrm{S}^{0}$ can be obtained by the slope and intercept of the fitting line, in which both positive values are obtained (Table 3). The positive value of $\Delta \mathrm{H}^{0}$ implies that the endothermic property of the present adsorption reaction, indicating that adsorption consumes energy. Therefore, $\mathrm{MB}$ adsorption increases with increasing temperature [40]. The positive value of $\Delta S^{0}$ indicates an increment in the randomness at the solid-liquid interface through MB adsorption onto the MPC composite [41].

$$
\begin{gathered}
\Delta \mathrm{G}^{0}=-\mathrm{RT}_{\ln K_{d}} \\
\ln K_{d}=\frac{\Delta \mathrm{S}^{0}}{\mathrm{R}}-\frac{\Delta \mathrm{H}^{0}}{\mathrm{RT}}
\end{gathered}
$$

\begin{tabular}{|c|c|c|c|c|}
\hline \multirow{2}{*}{$\Delta \mathrm{H}^{0}(\mathrm{~kJ} \mathrm{~mol}-1)$} & \multirow{2}{*}{$\Delta S^{0}\left(\mathrm{~J} \mathrm{~mol}^{-1} \mathrm{~K}^{-1}\right)$} & \multicolumn{3}{|c|}{$\Delta \mathrm{G}^{0}\left(\mathrm{~kJ} \mathrm{~mol}{ }^{-1}\right)$} \\
\hline & & $298 \mathrm{~K}$ & $308 \mathrm{~K}$ & $318 \mathrm{~K}$ \\
\hline 19.65 & 82.40 & -4.50 & -5.31 & -6.15 \\
\hline
\end{tabular}

Table 3. Adsorption thermodynamic parameter for MB adsorption on the MPC composite.

\subsection{Regeneration and Reuse of MPC}

Except for high adsorption capacity, the stability and reusability of adsorbents are also important. Therefore, regeneration and reuse of the MPC adsorbent was further investigated. The adsorption capacity of MB on MPC slightly decreases in successive cycles (Figure 5d). An Fe leaching test was performed to detect the Fe content in the aqueous solution by inductively coupled plasma (ICP). No Fe leaching was detected from the MPC in the aqueous phase after the completion of the MB adsorption, showing that the MPC has very high stability for MB adsorption. This observation could be interpreted by the strong chemical interaction between the $\mathrm{Fe}_{3} \mathrm{O}_{4}$ and PC, as detected by the XPS results. Previous results have indicated that not all the adsorbed dye could be removed from the surface of the adsorbent during the regeneration and reusability tests [42]. Similarly, the complete removal of the adsorbed MB on MPC was hardly achieved due to the strong interaction between the MB and MPC in the regeneration process, thereby leading to a decrease of adsorption capacity for $\mathrm{MB}$ in successive cycles. However, the adsorption capacity of MB still remains at $80.7 \%$ after reuse in the third cycle, indicating the good reusability of the as-prepared adsorbent. Furthermore, the adsorbent still has high magnetic sensitivity after three cycles.

\section{Conclusions}

In summary, MPC composite was synthesized via a simple one step solvothermal approach and employed for MB removal from aqueous solution. PMC showed very high adsorption performance because of the featured merits of $\mathrm{PC}$ and the $\mathrm{Fe}_{3} \mathrm{O}_{4}$ nanoparticles. Furthermore, the adsorbent could be 
easily recovered from aqueous solution by a magnet. The present work would shed light on the design and synthesis of efficient adsorbents based on the deposition of nano-sized $\mathrm{Fe}_{3} \mathrm{O}_{4} \mathrm{NPs}$ on a matrix with a high surface area and porous structure for dyes removal.

Supplementary Materials: The following are available online at http:/www.mdpi.com/2076-3417/9/14/2898/s1, Table S1: The adsorption capacity of MB onto various adsorbents.

Author Contributions: J.C. and M.M. prepared and characterized the samples. C.X. contributed reagents/materials/ analysis tools. G.F. and J.W. designed the experiments and wrote the paper. T.S., Y.W. and Y.Z. provided useful discussion.

Funding: This research was funded by the National Natural Science Foundation of China, grant number U1433101 and U1533118.

Conflicts of Interest: The authors declare no conflict of interest.

\section{References}

1. Sun, H.; Cao, L.; Lu, L. Magnetite/reduced graphene oxide nanocomposites: One step solvothermal synthesis and use as a novel platform for removal of dye pollutants. Nano Res. 2011, 4, 550-562. [CrossRef]

2. Bao, N.; Li, Y.; Wei, Z.; Yin, G.; Niu, J. Adsorption of Dyes on Hierarchical Mesoporous $\mathrm{TiO}_{2}$ Fibers and Its Enhanced Photocatalytic Properties. J. Phys. Chem. C 2011, 115, 5708-5719. [CrossRef]

3. Hu, M.L.; Hashemi, L.; Morsali, A. Pore size and interactions effect on removal of dyes with two lead(II) metal-organic frameworks. Mater. Lett. 2016, 175, 1-4. [CrossRef]

4. Chang, J.; Ma, J.; Ma, Q.; Zhang, D.; Qiao, N.; Hu, M.; Ma, H. Adsorption of methylene blue onto $\mathrm{Fe}_{3} \mathrm{O}_{4}$ /activated montmorillonite nanocomposite. Appl. Clay Sci. 2016, 119, 132-140. [CrossRef]

5. Yuan, R.; Guan, R.; Shen, W.; Zheng, J. Photocatalytic degradation of methylene blue by a combination of $\mathrm{TiO}_{2}$ and activated carbon fibers. J. Colloid Interface Sci. 2005, 282, 87-91. [CrossRef] [PubMed]

6. Yang, Z.; Li, M.; Yu, M.; Huang, J.; Xu, H.; Zhou, Y.; Song, P.; Xu, R. A novel approach for methylene blue removal by calcium dodecyl sulfate enhanced precipitation and microbial flocculant GA1 flocculation. Chem. Eng. J. 2016, 303, 1-13. [CrossRef]

7. Pavan, F.A.; Lima, E.C.; Dias, S.L.P.; Mazzocato, A.C. Methylene blue biosorption from aqueous solutions by yellow passion fruit waste. J. Hazard. Mater. 2008, 150, 703-712. [CrossRef]

8. Ai, L.; Zhang, C.; Liao, F.; Wang, Y.; Li, M.; Meng, L.; Jiang, J. Removal of methylene blue from aqueous solution with magnetite loaded multi-wall carbon nanotube: Kinetic, isotherm and mechanism analysis. J. Hazard. Mater. 2011, 198, 282-290. [CrossRef]

9. Lingamdinne, L.P.; Koduru, J.R.; Karri, R.R. A comprehensive review of applications of magnetic graphene oxide based nanocomposites for sustainable water purification. J. Environ. Manag. 2019, 231, 622-634. [CrossRef]

10. Ai, L.; Huang, H.; Chen, Z.; Wei, X.; Jiang, J. Activated carbon/ $\mathrm{CoFe}_{2} \mathrm{O}_{4}$ composites: Facile synthesis, magnetic performance and their potential application for the removal of malachite green from water. Chem. Eng. J. 2010, 156, 243-249. [CrossRef]

11. Ai, L.; Zhang, C.; Chen, Z. Removal of methylene blue from aqueous solution by a solvothermal-synthesized graphene/magnetite composite. J. Hazard. Mater. 2011, 192, 1515-1524. [CrossRef]

12. Sun, Z.; Liu, Z.; Han, B.; Wang, Y.; Du, J.; Xie, Z.; Han, G. Fabrication of Ruthenium-Carbon Nanotube Nanocomposites in Supercritical Water. Adv. Mater. 2005, 17, 928-932. [CrossRef]

13. Zhang, R.; Huang, X.; Zhong, B.; Xia, L.; Wen, G.; Zhou, Y. Enhanced microwave absorption properties of ferroferric oxide/graphene composites with a controllable microstructure. RSC Adv. 2016, 6, 16952-16962. [CrossRef]

14. Medvedev, A.E.; Neumann, A.; Ng, H.P.; Lapovok, R.; Kasper, C.; Lowe, T.C.; Anumalasetty, V.N.; Estrin, Y. Combined effect of grain refinement and surface modification of pure titanium on the attachment of mesenchymal stem cells and osteoblast-like SaOS-2 cells. Mater. Sci. Eng. C 2017, 71, 483-497. [CrossRef]

15. Hossain, M.M.; Shima, H.; Islam, M.A.; Hasan, M.; Lee, M. Simple synthesis process for ZnO sphere-decorated CNT fiber and its electrical, optical, thermal, and mechanical properties. RSC Adv. 2016, 6, 4683-4694. [CrossRef] 
16. Parida, K.; Satpathy, M.; Mohapatra, L. Incorporation of $\mathrm{Fe}^{3+}$ into $\mathrm{Mg} / \mathrm{Al}$ layered double hydroxide framework: Effects on textural properties and photocatalytic activity for $\mathrm{H}_{2}$ generation. J. Mater. Chem. 2012, 22, 7350-7357. [CrossRef]

17. Song, S.; Kim, J.; Lee, D.; Lee, J.; Min, T.; Chae, J.A.; Bae, J.S.; Lee, J.; Lee, J.S.; Park, S. The effect of Fe ${ }^{2+}$ state in electrical property variations of Sn-doped hematite powders. J. Am. Ceram. Soc. 2017, 100, 3928-3934. [CrossRef]

18. Que, W.; Sun, Z.; Lam, Y.; Chan, Y.; Kam, C. Effects of titanium content on properties of sol-gel silica-titania films via organically modified silane precursors. J. Phys. D Appl. Phys. 2001, 34, 471. [CrossRef]

19. Wang, W.; Zhang, Y.; Yang, Q.; Sun, M.; Fei, X.; Song, Y.; Zhang, Y.; Li, Y. Fluorescent and colorimetric magnetic microspheres as nanosensors for $\mathrm{Hg}^{2+}$ in aqueous solution prepared by a sol-gel grafting reaction and host-guest interaction. Nanoscale 2013, 5, 4958-4965. [CrossRef]

20. Wang, Q.; Ming, M.; Niu, S.; Zhang, Y.; Fan, G.; Hu, J.-S. Scalable Solid-State Synthesis of Highly Dispersed Uncapped Metal (Rh, Ru, Ir) Nanoparticles for Efficient Hydrogen Evolution. Adv. Energy. Mater. 2018, 8, 1801698. [CrossRef]

21. Zhu, W.; Song, H.; Zhang, L.; Weng, Y.; Su, Y.; Lv, Y. Fabrication of fluorescent nitrogen-rich graphene quantum dots by tin(iv) catalytic carbonization of ethanolamine. RSC Adv. 2015, 5, 60085-60089. [CrossRef]

22. Bharath, G.; Madhu, R.; Chen, S.M.; Veeramani, V.; Mangalaraj, D.; Ponpandian, N. Solvent-free mechanochemical synthesis of graphene oxide and $\mathrm{Fe}_{3} \mathrm{O}_{4}$-reduced graphene oxide nanocomposites for sensitive detection of nitrite. J. Mater. Chem. A 2015, 3, 15529-15539. [CrossRef]

23. Zhang, G.; Qu, J.; Liu, H.; Cooper, A.T.; Wu, R. CuFe $\mathrm{O}_{4}$ /activated carbon composite: A novel magnetic adsorbent for the removal of acid orange II and catalytic regeneration. Chemosphere 2007, 68, 1058-1066. [CrossRef]

24. Yang, N.; Zhu, S.; Zhang, D.; Xu, S. Synthesis and properties of magnetic $\mathrm{Fe}_{3} \mathrm{O}_{4}$-activated carbon nanocomposite particles for dye removal. Mater. Lett. 2008, 62, 645-647. [CrossRef]

25. Castro, C.S.; Guerreiro, M.C.; Gonçalves, M.; Oliveira, L.C.A.; Anastácio, A.S. Activated carbon/iron oxide composites for the removal of atrazine from aqueous medium. J. Hazard. Mater. 2009, 164, 609-614. [CrossRef]

26. Wang, P.; Cao, M.; Wang, C.; Ao, Y.; Hou, J.; Qian, J. Kinetics and thermodynamics of adsorption of methylene blue by a magnetic graphene-carbon nanotube composite. Appl. Surf. Sci. 2014, 290, 116-124. [CrossRef]

27. Zhang, W.; Zhang, L.Y.; Zhao, X.J.; Zhou, Z. Citrus pectin derived ultrasmall $\mathrm{Fe}_{3} \mathrm{O}_{4} @ \mathrm{C}$ nanoparticles as a high-performance adsorbent toward removal of methylene blue. J. Mol. Liq. 2016, 222, 995-1002. [CrossRef]

28. Zhou, H.; Yan, B.; Lai, J.; Liu, H.; Ma, A.; Chen, W.; Jin, X.; Zhao, W.; Zhang, G. Renewable biomass derived hierarchically porous carbonaceous sponges and their magnetic nanocomposites for removal of organic molecules from water. J. Ind. Eng. Chem. 2018, 58, 334-342. [CrossRef]

29. Zhang, H.; Chen, L.; Li, L.; Yang, Y.; Liu, X. Magnetic porous carbon microspheres synthesized by simultaneous activation and magnetization for removing methylene blue. J. Porous Mater. 2017, 24, 341-353. [CrossRef]

30. Mao, G.Y.; Bu, F.X.; Jiang, D.M.; Zhao, Z.J.; Zhang, Q.H.; Jiang, J.S. Synthesis, Characterization and Adsorption Properties of Magnetic $\gamma-\mathrm{Fe}_{2} \mathrm{O}_{3} / \mathrm{C}$ Nanocomposite. J. Nanosci. Nanotechnol. 2015, 15, 5924-5932. [CrossRef]

31. Zheng, J.; Cheng, C.; Fang, W.J.; Chen, C.; Yan, R.W.; Huai, H.X.; Wang, C.C. Surfactant-free synthesis of a $\mathrm{Fe}_{3} \mathrm{O}_{4} @ \mathrm{ZIF}-8$ core-shell heterostructure for adsorption of methylene blue. CrystEngComm 2014, 16, 3960-3964. [CrossRef]

32. Miranda, L.D.L.; Bellato, C.R.; Fontes, M.P.F.; de Almeida, M.F.; Milagres, J.L.; Minim, L.A. Preparation and evaluation of hydrotalcite-iron oxide magnetic organocomposite intercalated with surfactants for cationic methylene blue dye removal. Chem. Eng. J. 2014, 254, 88-97. [CrossRef]

33. Shi, H.; Li, W.; Zhong, L.; Xu, C. Methylene Blue Adsorption from Aqueous Solution by Magnetic Cellulose/Graphene Oxide Composite: Equilibrium, Kinetics, and Thermodynamics. Ind. Eng. Chem. Res. 2014, 53, 1108-1118. [CrossRef]

34. Feng, J.; Wang, Y.; Zou, L.; Li, B.; He, X.; Ren, Y.; Lv, Y.; Fan, Z. Synthesis of magnetic ZnO/ZnFe $\mathrm{O}_{4}$ by a microwave combustion method, and its high rate of adsorption of methylene blue. J. Colloid Interface Sci. 2015, 438, 318-322. [CrossRef]

35. Xie, G.; Xi, P.; Liu, H.; Chen, F.; Huang, L.; Shi, Y.; Hou, F.; Zeng, Z.; Shao, C.; Wang, J. A facile chemical method to produce superparamagnetic graphene oxide- $\mathrm{Fe}_{3} \mathrm{O}_{4}$ hybrid composite and its application in the removal of dyes from aqueous solution. J. Mater. Chem. 2012, 22, 1033-1039. [CrossRef] 
36. Hameed, B.H.; Ahmad, A.L.; Latiff, K.N.A. Adsorption of basic dye (methylene blue) onto activated carbon prepared from rattan sawdust. Dyes Pigment 2007, 75, 143-149. [CrossRef]

37. Ng, C.; Losso, J.N.; Marshall, W.E.; Rao, R.M. Freundlich adsorption isotherms of agricultural by-productbased powdered activated carbons in a geosmin-water system. Bioresour. Technol. 2002, 85, 131-135. [CrossRef]

38. Weber, T.W.; Chakravorti, R.K. Pore and solid diffusion models for fixed-bed adsorbers. AlChE J. 1974, 20, 228-238. [CrossRef]

39. McKay, G. Adsorption of dyestuffs from aqueous solutions with activated carbon I: Equilibrium and batch contact-time studies. J. Chem. Technol. Biotechnol. 1982, 32, 759-772. [CrossRef]

40. Ali, R.M.; Hamad, H.A.; Hussein, M.M.; Malash, G.F. Potential of using green adsorbent of heavy metal removal from aqueous solutions: Adsorption kinetics, isotherm, thermodynamic, mechanism and economic analysis. Ecol. Eng. 2016, 91, 317-332. [CrossRef]

41. Tan, I.A.W.; Ahmad, A.L.; Hameed, B.H. Adsorption of basic dye on high-surface-area activated carbon prepared from coconut husk: Equilibrium, kinetic and thermodynamic studies. J. Hazard. Mater. 2008, 154, 337-346. [CrossRef]

42. Gong, J.L.; Wang, B.; Zeng, G.M.; Yang, C.P.; Niu, C.G.; Niu, Q.Y.; Zhou, W.J.; Liang, Y. Removal of cationic dyes from aqueous solution using magnetic multi-wall carbon nanotube nanocomposite as adsorbent. J. Hazard. Mater. 2009, 164, 1517-1522. [CrossRef]

(C) 2019 by the authors. Licensee MDPI, Basel, Switzerland. This article is an open access article distributed under the terms and conditions of the Creative Commons Attribution (CC BY) license (http://creativecommons.org/licenses/by/4.0/). 